\title{
Assessment of Knowledge about Priorities of Nurses' Responsibilities at Emergency Departments in Baghdad Teaching Hospitals
}

\author{
Amena H. Jasem, Msc.N ${ }^{1}$, Dr. Widad K. Mohammad, PhD ${ }^{2}$ \\ ${ }^{I}$ (Academic Nurse, Adults Nursing Department, College of Nursing, University of Baghdad, Iraq) \\ ${ }_{2}^{2}$ (Assistant Professor, Adults Nursing Department, College of Nursing, University of Baghdad, Iraq)
}

\begin{abstract}
Priorities of responsibility are essential function in emergency department. Effective priorities of responsibilities system aim to ensure that patients who seek emergency care receive an appropriate attention, in a suitable location, with the requisite degree of urgency. Such an emergency care is an initial in response to clinical need rather than order of arrival. This study therefore aimsto assess the knowledge and skills of priorities of responsibilities among nurses who work in the Emergency Departments in Baghdad Teaching Hospitals.

Objective:The study objective is to assess knowledge about priorities of nurses' responsibilities at Emergency Departments and to determine the association between knowledge about prioritization of nurses' responsibilities and demographic characteristics of age, level of education and gender.

Methodology:A descriptive study was conducted in the Baghdad Teaching Hospitals. Starting from December $20^{\text {th }}, 2015$ up to the August 30th, 2016. A purposive "non-probability" sample of (80) nurses, who have been working in emergency departments, were selected from Baghdad Teaching Hospitals which include Al-Yarmook Teaching Hospital, Baghdad Teaching Hospital, Al-Kindy Teaching Hospital, Al-Karama Teaching Hospital, and Al-Kadhmiyia Teaching Hospital.

Descriptive statistical measures were used to analyze the data.The data were collected through the use of constructed questionnaire, which consists of two parts; (1) Demographic data which consists of (6) items, and (2) Nurses' knowledge which consists of (28) items. Thereliability was determined through a pilot study.The validity was determined through a panel of (14) experts. Descriptive statistical measures (frequency, percentage, mean of score), and inferential statistical measures (Chi-square and Relative Sufficiency) were used for the data analysis.
\end{abstract}

Results: The study results indicate thatmore than a third of the study participants are of the 23-27 years-old age group (35\%), more than a half of them are males (57.5\%), more than a third of them are Secondary Nursing School graduates (35\%), less than two fifth of them had (1-5) years of experience in hospital (37.5\%),most of them had 1-5 years of experience in emergency department (72.5\%), and more than two fifth of them had one training session $(42.5 \%)$.

Conclusions:The majority of the nurses had poor knowledge concerning priorities of responsibilities and there was non-significant association between the nurses' knowledge and their gender and age, but there is a significant association between nurses' knowledge and their educational level.

Recommendations:The researchersrecommend that the referral hospitals should develop procedure manuals that provide detailed information about all priorities of responsibilities. The procedure manual should be subjected to an annual audit, and active steps should be initiated to remedy identified deficiencies.

\section{Introduction}

Emergency nursing is a specialized area of practice. Emergency health care has been touched by critical changes in recent years. The volume of patient' visiting emergency centers has increased dramatically to the extent that crowding, flow, and throughput have been added to the daily vocabulary of emergency nurses. In many locations, steady streams of anxious, vulnerable people who' have complex medical conditions or are without care options appear at the emergency department ${ }^{(1)}$. The triage nurse in emergency department is the first person that a patient encounter when presenting for emergency care to the department. Triage nurses' knowledge and experience have been as influential factors in triage decision-making ${ }^{(2)}$. Setting priorities is also identified as the first step in the planning phase of the teaching-learning process between nurse's and clients, where the priorities for teaching are based on the nursing diagnoses and the learning objectives established for the client ${ }^{(3)}$.Priority setting is a challenge at all levels (global, national, and local) and for all contexts in health systems because demand for health care usually exceeds available resources ${ }^{(4)}$. With each passing decade, the role and practice of the emergency nurse has continued to develop. As the role of the emergency nurse and practice environment continue to transform, the educational needs and priorities will continue to evolve and expand ${ }^{(5)}$. 


\section{Methodology}

A descriptive design was conducted in the emergency departments started from December $20^{\text {th }}, 2015$ to August $30^{\text {th }}$, 2016. A purposive "non-probability"sample of (80) nurses, who have been working atemergency departments, were selected from Baghdad Teaching Hospitalswhich includeAl-Yarmook Teaching Hospital, Baghdad Teaching Hospital, and Al-KindyTeaching Hospital,Al-KaramaTeaching Hospital,and Al-Kadhmiyia Teaching Hospital. The data were collected in the period from March $22^{\text {nd }}, 2016$ to May4 ${ }^{\text {th }}, 2016$. The data were collected by a structured interview with nurses. This interview lasts for about 10 to 15 minutes for each participant. The questionnaire was composed of two parts;Part 1: Demographic Characteristics which includes six items of age, gender, level of education, number of years in employment, number of years in the emergencydepartments, and number of training sessions, Part II: Nurses' knowledge aboutpriorities of responsibilitieswhich includes (28) itemsrelated to priority setting, primary and secondary survey and lifesaving.A pilot study was carried out for the period between March $1^{\text {st }}, 2016$ and March $20^{\text {th }} ; 2016$ on (10) nurses who work at emergency departments in Baghdad Teaching Hospitalto determine the reliability of the questionnaire and content validity was carried out through the (14) experts. Descriptive and inferential statistical measures were used to analyze the data.

\section{Results}

Table 1.Participants' Socio-demographicCharacteristics $(\mathrm{N}=80)$

\begin{tabular}{|c|c|c|}
\hline Variables & \multirow{2}{*}{ Frequency } & \multirow{2}{*}{ Percent } \\
\hline Age Groups (Years) & & \\
\hline $18-22$ & 18 & 22.5 \\
\hline $23-27$ & 28 & 35 \\
\hline $28-32$ & 15 & 18.8 \\
\hline $33-37$ & 7 & 8.8 \\
\hline $38-42$ & 12 & 15 \\
\hline Gender & Frequency & Percent \\
\hline Male & 46 & 57.5 \\
\hline Female & 34 & 42.5 \\
\hline Educational Level & Frequency & Percent \\
\hline Primary nursing school graduate & 5 & 6.3 \\
\hline Secondary nursing school graduate & 28 & 35 \\
\hline High institute graduate & 22 & 27.5 \\
\hline Collage of nursing graduate & 25 & 31.3 \\
\hline Years of experience in hospitals & Frequency & Percent \\
\hline $1-5$ & 30 & 37.5 \\
\hline $6-10$ & 21 & 26.3 \\
\hline $11-15$ & 12 & 15 \\
\hline $16-20$ & 2 & 2.5 \\
\hline 21 and more & 15 & 18.8 \\
\hline Years of experience in emergency & Frequency & Percent \\
\hline $1-5$ & 58 & 72.5 \\
\hline $6-10$ & 14 & 17.5 \\
\hline $11-15$ & 3 & 3.8 \\
\hline $16-20$ & 2 & 2.5 \\
\hline 21 and more & 3 & 3.8 \\
\hline Training Session & Frequency & Percent \\
\hline None & 15 & 18.8 \\
\hline 1 & 34 & 42.5 \\
\hline 2 & 14 & 17.5 \\
\hline 3 & 5 & 6.3 \\
\hline More than 3 & 12 & 15 \\
\hline
\end{tabular}

Table (1)reveals that more than a third of the study participants are of the 23-27 years-old age group $(n=18 ; 35 \%)$, more than a half of them are males $(n=46 ; 57.5 \%)$, more than a third of them are Secondary Nursing School graduates $(n=28 ; 35 \%)$, less than two fifth of them had (1-5) years of experience in hospital $(n=30 ; 37.5 \%)$, most of them had 1-5 years of experience in emergency department $(n=58 ; 72.5 \%)$, and more than two fifth of them had one training session $(n=34 ; 42.5 \%)$.

Table 2.Mean of Score of Nurses' Knowledge Toward Principle of Priority Setting

\begin{tabular}{|c|l|c|c|c|c|c|}
\hline \multicolumn{2}{|c}{ Items related to principle of priority setting } & Yes & No & \multirow{2}{*}{ M.S } & \multirow{2}{*}{ R. S } & \multirow{2}{*}{ Assessment } \\
\cline { 3 - 4 } & Frequency & Frequency & & & \\
\hline 1 & Identify the priority needs of patients and Examination & 58 & 22 & 1.72 & 86 & Good \\
\hline
\end{tabular}




\begin{tabular}{|c|l|c|c|c|c|c|}
\hline 2 & Priority to the needs of patients is not necessary & 70 & 10 & 1.12 & 56 & Fair \\
\hline 3 & $\begin{array}{l}\text { Verification of pathological symptomsthat threaten the } \\
\text { patient's life }\end{array}$ & 52 & 28 & 1.65 & 82.5 & Good \\
\hline 4 & $\begin{array}{l}\text { Know the symptoms of the disease or themechanism of } \\
\text { injury is not necessary }\end{array}$ & 65 & 15 & 1.18 & 59 & Fair \\
\hline 5 & $\begin{array}{l}\text { Determine the mental state by knowing thepeople and the } \\
\text { place, time and event }\end{array}$ & 55 & 25 & 1.68 & 84 & Good \\
\hline
\end{tabular}

\section{S. = Mean of Scores, R. S. = Relative Sufficiency}

Table (2) showsthat the majority of nurses reflect a good knowledge abouttheprinciple of priority setting in the items $(1,3,5)$ and the minority of them reflect a fair knowledge in items $(2$, 4).

Table 3.Mean of Score of Nurses' Knowledge Toward Primary survey - Circulation

\begin{tabular}{|c|l|c|c|c|c|c|}
\hline \multicolumn{2}{|c|}{ C. Items related to Circulation } & Yes & No & \multirow{2}{*}{ M.S } & \multirow{2}{*}{ R.S } & Assessment \\
\cline { 2 - 5 } & Frequency & Frequency & & & Very Good \\
\hline 2 & Look for level of consciousness & 72 & 8 & 1.9 & 95 & Fair \\
\hline 3 & Look for depth of breath & 9 & 71 & 1.11 & 55.5 & Very Good \\
\hline 4 & $\begin{array}{l}\text { Look for internal hemorrhageswelling /distension, } \\
\text { discoloration under skin }\end{array}$ & 73 & 7 & 1.91 & 95.5 & \multirow{2}{*}{ Fair } \\
\hline 5 & $\begin{array}{l}\text { In penetrating neck injuries and venous injuries must put } \\
\text { thepatient's head to the top to prevent air embolism }\end{array}$ & 60 & 20 & 1.25 & 62.5 & \multirow{2}{*}{ Good } \\
\hline 6 & Don't listen to heart sounds & 64 & 16 & 1.2 & 60 & Fair \\
\hline 7 & $\begin{array}{l}\text { Palpate to know the skintemperature and } \\
\text { diaphoresis(moisture) }\end{array}$ & 15 & 65 & 1.18 & 59 & Fair \\
\hline 8 & Monitor for limb injury threatening the viability of the limb & 13 & 67 & 1.16 & 58 & Fair \\
\hline 9 & Check capillary refile & 17 & 63 & 1.21 & 60.5 & Fair \\
\hline 10 & Check the level of oxygen & 70 & 10 & 1.87 & 93.5 & Very good \\
\hline 11 & Look for femoral artery & 16 & 64 & 1.2 & 60 & Fair \\
\hline
\end{tabular}

\section{S. = Mean of Scores, R. S. = Relative Sufficiency}

Table (3) showsthat the majority of nurses reflect fair knowledge aboutPrimary survey - Circulation in the items $(2,4,6,7,8,9,11)$, and very good knowledge in the items $(1,3,10)$, and good knowledge in item (5).

Table 4. Mean of Score of Nurses' Knowledge Toward Lifesaving

\begin{tabular}{|c|c|c|c|c|c|c|}
\hline \multirow{2}{*}{\multicolumn{2}{|c|}{ H. Items related to lifesaving }} & Yes & No & \multirow{3}{*}{$\begin{array}{l}\text { M.S } \\
1.72\end{array}$} & \multirow{3}{*}{$\begin{array}{c}\text { R. S } \\
86\end{array}$} & \multirow{3}{*}{$\frac{\text { Assessment }}{\text { Good }}$} \\
\hline & & \multirow{2}{*}{$\frac{\text { Frequency }}{58}$} & \multirow{2}{*}{$\begin{array}{c}\text { Frequency } \\
22\end{array}$} & & & \\
\hline 1 & Measure heart and circulation by taping on patient & & & & & \\
\hline 2 & Control and stop the bleeding, if apparent & 75 & 5 & 1.93 & 96.5 & Very good \\
\hline 3 & $\begin{array}{l}\text { Measured and dc shock is taken in ventricular fibrillation or } \\
\text { atrial fibrillation }\end{array}$ & 62 & 18 & 1.22 & 61 & Fair \\
\hline $4 a$ & $\begin{array}{l}\text { Actions taken in the case of class give blood for the patient } \\
\text { to adifferent class blood is give mannitol }\end{array}$ & 35 & 45 & 1.56 & 78 & Good \\
\hline $4 \mathrm{~b}$ & $\begin{array}{l}\text { Actions taken in the case of class give blood for the patient } \\
\text { to a different class blood is give oxygen }\end{array}$ & 56 & 24 & 1.7 & 85 & Good \\
\hline $4 \mathrm{c}$ & $\begin{array}{l}\text { Actions taken in the case of class give blood for the patient } \\
\text { to a different class blood is give glucose saline }\end{array}$ & 65 & 15 & 1.18 & 59 & Fair \\
\hline $5 a$ & $\begin{array}{l}\text { The steps to be carried out upon the arrival of the patient } \\
\text { who is suffering from convulsions is give the patient normal } \\
\text { saline }\end{array}$ & 67 & 13 & 1.16 & 58 & Fair \\
\hline $5 b$ & $\begin{array}{l}\text { The steps to be carried out upon the arrival of the patient } \\
\text { who is suffering from convulsions is give the patient beta } \\
\text { blocker }\end{array}$ & 64 & 16 & 1.2 & 60 & Fair \\
\hline
\end{tabular}




\begin{tabular}{|c|c|c|c|c|c|c|}
\hline $5 c$ & $\begin{array}{l}\text { The steps to be carried out upon the arrival of the patient } \\
\text { who is suffering from convulsions is check airway }\end{array}$ & 50 & 30 & 1.62 & 81 & Good \\
\hline $5 d$ & $\begin{array}{l}\text { The steps to be carried out upon the arrival of the patient } \\
\text { who is suffering from convulsions is check breathing }\end{array}$ & 75 & 5 & 1.93 & 96.5 & Verygood \\
\hline $5 e$ & $\begin{array}{l}\text { The steps to be carried out upon the arrival of the patient } \\
\text { who is sufferingfrom convulsions is check circulation }\end{array}$ & 12 & 68 & 1.15 & 57.5 & Fair \\
\hline $5 f$ & $\begin{array}{l}\text { The steps to be carried out upon thearrival of the patient who } \\
\text { is sufferingfrom convulsions is put the patient on right } \\
\text { position }\end{array}$ & 19 & 61 & 1.23 & 61.5 & Fair \\
\hline
\end{tabular}

\section{S. = Mean of Scores, R. S. = Relative Sufficiency}

Table (4) shows that the majority of nurses reflect fair knowledge about toward lifesaving was present in the items $(3,4 \mathrm{c}, 5 \mathrm{a}, 5 \mathrm{~b}, 5 \mathrm{e}, 5 \mathrm{f})$, and very good knowledge in the items $(2,5 \mathrm{~d})$, and good knowledge in the items $(1,4 a, 4 b, 5 c)$.

Table 5.Association Between Nurses' Knowledge and Their Age Group ( $\mathrm{N}=80)$

\begin{tabular}{|l|c|c|c|c|}
\hline Age Groups(Years) Knowledge & Fair & Good & Very Good & Total \\
\hline $18-22$ & 0 & 18 & 0 & 18 \\
\hline $23-27$ & 0 & 28 & 0 & 28 \\
\hline $28-32$ & 0 & 15 & 0 & 15 \\
\hline $33-37$ & 0 & 7 & 0 & 7 \\
\hline $38-42$ & 1 & 10 & 1 & 12 \\
\hline Total & 1 & 78 & 1 & 80 \\
\hline \multicolumn{2}{|l|}{$\chi 2$ crit. $=15.51$} & $\mathrm{P} \leq 0.05$ & \\
\hline
\end{tabular}

M. S. = Mean of Scores, R. S. = Relative Sufficiency

Table (4) shows that there is no significant association between nurses' knowledge and their age group.

Table 6.Association Between Nurses' Knowledge and Their Gender (N=80)

\begin{tabular}{|c|c|c|c|c|}
\hline $\mathrm{C}_{\text {Gender }}$ Knowledge & Fair & Good & Very Good & Total \\
\hline$=$ & 1 & 44 & 1 & 46 \\
\hline Female & 0 & 34 & 0 & 34 \\
\hline Total & 1 & 78 & 1 & 80 \\
\hline$\chi^{2}$ obs. $=1.510$ & $\mathrm{df}=2$ & & & \\
\hline
\end{tabular}

$\mathrm{df}=$ Degree of Freedom, $\chi 2$ obs. $=$ Chi-square Observed, $\chi 2$ crit. $=$ Chi-square Critical

Table (6) shows that there is no significant association between nurses' knowledge and theirgender.

Table 7.Association Between Nurses' Knowledge and Their Educational Level $(\mathrm{N}=80)$

\begin{tabular}{|l|c|c|c|}
\hline $\begin{array}{l}\text { Knowledge } \\
\text { Education }\end{array}$ & Good & Very good & Total \\
\hline Primary nursing school & 5 & 0 & 5 \\
\hline Secondary nursing school & 10 & 18 & 28 \\
\hline High institute & 22 & 0 & 22 \\
\hline College of nursing & 18 & 7 & 25 \\
\hline Total & 55 & 25 & 80 \\
\hline$\chi 2$ obs. $=26.619 \quad \mathrm{df}=6$ & $\chi 2$ crit. $=12.59$ & \multicolumn{2}{|c|}{ P-value $=0.000$} \\
\hline
\end{tabular}

$\mathrm{df}=$ Degree of Freedom, $\chi 2$ obs. $=$ Chi-square Observed, $\chi 2$ crit. $=$ Chi-square Critical

Table (7) shows that there is high significant association between nurses' knowledge and their educationallevel. 


\section{Discussion}

Discussion of the Socio-demographic Characteristics of Studied Sample (Table 1):

Through the data analysis of distribution of the socio-demographic variables, (Table 1)reveals that approximately half of the study sample $(57.5 \%)$ were male. This result disagrees with the study which is done by Andersson $(2007){ }^{(6)}$ who showed that $(16 \%)$ of nurses were females. This finding agrees with the studies supported by Al-Ftlawi, $(2012){ }^{(7)}$ and Mustafa(2014) ${ }^{(8)}$, whoreported that the majority of study nurses were males.

The highest proportion (35.0\%) of the sample are within the age group (23-27). This result disagrees with a study done by Rutto, (2012) who showed that the majority (70.6\%) of participants were aged between 30 to 39 years ${ }^{(9)}$.

Concerning the level of education, the resultsrevealed that the one third of the sample (35\%) were graduated from secondary nursing school. This finding disagree with studies done by Rutto (2012) ${ }^{(9)}$ who showed that $(44.1 \%)$ of the nurses had institute graduate and the study done by Mustafa $(2014){ }^{(8)}$ found that the majority of nurses have bachelor's degree (41.2\%).

Regarding years of experiences in hospitals, one third of them (37.5\%) are within (1-5) years, this result is similar with which is study done by Mahmood $(2014){ }^{(10)}$ who shows that more than third $(35.0 \%)$ of the nurses have (1-5) years' experience in hospital.

Regardingyears of experiences in emergency, most of them had (1-5) experiences years in emergency departments that represented $(72.5 \%)$. This finding comes in agreement with Mahmood $(2013){ }^{(11)}$ who reported that the and (60\%) of the nurses have (5-10) years experiences at emergencydepartments. And disagree with studydone by Vigil(2015) ${ }^{(11)}$ who found that the majority of the samples had (14) years of experience.

Regarding the numbers of training session, the study demonstrated that less than half (42.5\%) had (1) training course. And this result disagrees with the study done by Mustafa $(2014)^{(8)}$ the finding show that $(61.2 \%)$ not have any formal training course on cardiopulmonary resuscitation. And the study done by Mahmood (2014) ${ }^{(10)}$ show that $52.5 \%$ of nurses had (1-5) training session;in Iraq,related to the emergency care and $15 \%$ of them have out of Iraq training session.

\section{Discussion of nurses' knowledge Priority Setting:}

Table(2) showed that the mean of score for item of nurses' knowledge toward Priority Settingwas present the majority of nurses reflect a good knowledge in items $(13,5)$ and the minority of nurses reflect a fair knowledge in items $(2,4)$. Based on the researchers' point of view, these finding mean thatthe nurseswho work in ED had an enough knowledge concerning priority setting but needed to develop their knowledge to be up -to data of any knowledge related to priority setting. This result disagrees the study done by Robert,2010shows that the more than half $(58 \%)$ of the respondents had poor knowledge on waiting time limits for patient's triaged categories, among the four hospital observed, only one had triage nurse allocated for patients' triage. ${ }^{(12)}$

\section{Discussion of nurses' knowledge toward primary survey-circulation:}

Tables (3) showed the mean of score for item of nurses' knowledge toward Primary survey Circulation was present that the majority of nurses reflect fair knowledge in items $(2,4,6,7,8,9,11)$, and very good knowledge in items $(1,3,10)$, and good knowledge in item (5).

Based on the researchers' point of view, these finding mean that nurses who work in ED had fair level of knowledge concerningprimary survey-circulation and all ED staff nurses needed to develop their knowledge to be up-to-date of any knowledge related to primary survey-circulation.

\section{Discussion of nurses' knowledge toward lifesaving:}

Table (4) showed the mean of score for item of nurses' knowledge toward lifesaving was present that the majority of nurses reflect fair knowledge in items $(3,4 c, 5 a, 5 b, 5 e, 5 f)$ and very good knowledge in items $(2,5 d)$ and good knowledge in items $(1,4 a, 4 b, 5 c)$.

Based on the researcher 's point of view, these finding mean that nurses who work in ED had fair level of knowledge concerning lifesaving and all ED staff nurses needed to develop their knowledge to be up-to-date of any knowledge related to lifesaving. This result is supported by a study conducted by Nabil (2013) thatshowed the nurses were having an unsatisfactory knowledge about cardiac dysrhythmias, connecting patient to monitor, recording 12- lead ECG, cardiopulmonary resuscitation, defibrillation, emergency care and emergency medication and majority of the nurses were having an unsatisfactory practice levels about management of fatal dysrhythmia connecting patient to monitor, recording 12- lead ECG, cardiopulmonary resuscitation,defibrillation, emergency care and emergency medication ${ }^{(13)}$. 


\section{Discussion of Association Between Association between nurses' knowledge and their demographic characteristic Data (Tables 4-7):}

Age:The data analysis of Table (4) showedthat there was non-significant association at $\mathrm{p}$-value $(\mathrm{P} \leq 0.05)$ level between nurses' knowledge and their age. This result agrees with study done by Mustafa (2014) ${ }^{(8)}$.There was non-significant association between the nurses' knowledge about cardiopulmonary resuscitation procedure and their age.

Gender:Table (5) indicates showed that there was non-significant relationship at p-value $(\leq 0.05)$ level between nurse's knowledge and their gender. This result agrees with study conducted by (Mustafa, 2014) ${ }^{(8)}$ who showedthat there was non-significant association between the nurses' knowledge and their gender.

Level of education: Table (7) revealed that there was a highly significant relationship at p-value $(0.000)$ between nurses' knowledge and their level of education. This result disagrees with that conducted by Robert $(2010){ }^{(12)}$ who present that there was significant relationship between nurses' knowledge and their education level.

\section{Conclusion}

The researchers concluded that the majority of the nurses had poor knowledge concerning priorities of responsibilities and there was non-significant association between the nurses' knowledge and their gender and age, but there is a significant association between nurses' knowledge and educational level.

\section{Recommendations}

The researchers recommend that the referral hospitals should develop procedure manuals that provide detailed information about all priorities of responsibilities, the procedure manual should be subject to an annual audit, and active steps should be initiated to remedy identified deficiencies.

\section{References}

[1]. Emergency Nurses Association. Position statement: End-of-life care in the emergency department (2010). Des Plaines, IL.

[2]. Considine, J., Botti, M., \& Thomas, S. Do knowledge and experience have specific roles in triage decision-making? Academic Emergency Medicine.2007;14, 722-726.

[3]. Potter, P. A. and Perry, A. G. Fundamentals of Nursing. Concepts, Process, and Practice. (4th ed.). (1997), St Louis: Mosby.

[4]. Dresser R. Priority Setting in Biomedical Research. Virtual Mentor, 2009, 11(4): 322-325

[5]. Heller, B. R., Oros, M. T., \& Durney-Crowley, J. The future of nursing education: 10 trends to watch. Nursing and Health Care Perspectives, (2000). 21(1), 9-13

[6]. Adams, j, Anderson, S., Bateman, H., DjOnokusumo, E., Hellmor, R., et.al., Dictionary of Nursing,2nd edition, London: an and c black, 2007, pp22,52,204,205.

[7]. Al-Ftlawi, D. Determination of Nurses' Knowledge Toward Care Provided to Patients with Acute Myocardial Infraction in AlNajaf City. kufa journal for nursing sciences,2012; Vol.2, No.2: Pp.1-11.

[8]. Al-Janabi, M. A. Journal of Kufa for Nursing Science, Assessment of Nurses' Knowledge towards Cardiopulmonary Resuscitation Vol. 4 No. 1: 2014, pp.8-10

[9]. Japheth Rutto, James Mwaura, Angeline Chepchirchir, Theresa Odero Nurse's knowledge, attitude and practice on the initial management of acute poisoning among adult casualties / Open Journal of Nursing 2 (2012) 149-156.

[10]. Shatha Mahmood Niazy, Evaluation of Nursing Practices for Patients with Burns 2014 vol:4 no:3: pp 77-85.

[11]. Vigil JM, Alcock J, Coulombe P, McPherson L, Parshall M, Murata A, et al. Ethnic Disparities in Emergency Severity Index Scores among U.S. Veteran's Affairs Emergency Department Patients. PLoS ONE 10(5): e126792. doi: (2015), 10.1371/journal.pone.0126792.

[12]. Alyoce, Robert.: assessment of knowledge and skills of triaging amongst nurses working in emergency departments. (Thesis)university of health and allied science. 2010.Pp:30-40.

[13]. Rasha. Nabil, Assessment of Nurses Knowledge and Practice in Cardiac Dysrhythmia among Critical,2013. 